\title{
Multiculturalism, Migration, and the Politics of I dentity in Singapore
}

\author{
LIAN, Kwen Fee \\ Brunei: Editora UBD, 2015 \\ Por: Isadora de Lima Branco
}

\begin{abstract}
O multiculturalismo, considerado como solução para o gerenciamento das diferenças, tem se tornado cada vez mais um discurso global orientador de políticas, especialmente com o fim da popularidade do modelo assimilacionista, interpretado como opressivo (OKIN, 2010). O apontamento dos desafios e problemas desse modelo multicultural, portanto, apesar de pouco empreendido, revela-se neste momento como imprescindível para a academia e para o direcionamento de políticas. Desta forma, assim como Susan Okin (2010) formula uma reflexão importante a respeito dos limites da priorização dos direitos de grupo nos Estados liberais, a obra "Multiculturalism, Migration, and the Politics of Identity in Singapore" elabora uma série de reflexões acerca dos desafios e problemas do multiculturalismo em Singapura. Essa atividade é realizada especialmente com o objetivo de compreender as políticas e lógicas que formaram a identidade no país, bem como demarcar os limites e falhas do modelo multicultural que, segundo o autor, diferenciam-se dos desafios de Estados liberais já que esses últimos se estabelecem como modelo comunitário de multiculturalismo.
\end{abstract}

Assim, é importante ressaltar a introdutória, mas consistente diferenciação entre o multiculturalismo Singapurense, de maneira geral, Asiático, e os multiculturalismos de Estados liberais como o canadense. Nesse movimento, fica clara a tentativa de evitar a aplicação direta de conceitos e características dos multiculturalismos ocidentais para a análise dos desafios encontrados em Singapura, reprimindo "orientalismos" que perpassam os estudos sobre as diferenças culturais, ou seja, as tentativas dos acadêmicos de explicar o Oriente tomando o Ocidente como horizonte, ponto de partida (SAID, 1996). Apesar desse empreendimento interessante e bem encadeado pela revisão bibliográfica de autores regionais e resgate histórico minucioso, estranha-se o deslize na realização de uma comparação linear e valorativa entre o multiculturalismo canadense e singapurense, na afirmação que "o multiculturalismo em Singapura distingue-se por sua versão fortalecida, bem a frente do Canadá e da Austrália" (LIAN, 2015, p. 21), principalmente após as diferenciações que pareciam reprimir comparações de tal espécie e 
destacar as distintas características e desafios que o modelo assume nesses locais. Especificamente, destaca-se que o desafio enfrentado pelos Estados liberais consiste em equilibrar e mediar entre os direitos individuais e coletivos, enquanto o desafio dos Estados comunitários consiste em conciliar as múltiplas demandas dos diversos grupos dentro das estruturas hierárquicas que os grupos estabelecem diante dos indivíduos.

Ainda baseando-se na ideia de diferença entre as práticas do multiculturalismo, a obra "Multiculturalism, Migration, and the Politics of Identity in Singapore" é um estudo de caso que reúne 7 artigos em torno de análises históricas e revisões bibliográficas para a compreensão das dinâmicas de formação de identidades e das características do multiculturalismo singapurense, análises organizadas pelo professor de sociologia do Instituto de Estudos Asiáticos, da Universidade de Brunei Darussalam, Kwen Lian. Realizadas por meio de um encadeamento de argumentos consistentes e claros, as análises permitem o desmonte do mito do multiculturalismo como modelo ideal e integralmente inclusivo como seria possível depreender da obra de Kymlica (2006), especialmente devido à polarização racial e ao essencialismo do quadrinômio simplificado de raças consideradas formadoras do Estado singapurense: Chineses, Malaios, Indianos e outros (CMIO).

Assim, a interessante dinâmica da reunião dos artigos, os quais realizam resgates históricos para explicar o desenvolvimento das diversas identidades do país, incluídas ou excluídas no quadrinômio, permite que o leitor perceba aos poucos a coexistência de continuidades e descontinuidades que construíram a realidade política-social do Estado multicultural de Singapura, que possui como marco histórico de referência a independência do país. Para isso, o livro destaca o processo de descolonização e a formação das primeiras políticas multiculturais, as identidades que ficaram excluídas desse processo, como a Tamil Muslim - comunidade muçulmana originária do sul da Índia - e os CeylonTamils - referente ao grupo étnico indiano que recebeu status social elevado durante o período colonial pela predominância de alta qualificação profissional e educacional. Ademais, o livro destaca os estereótipos que norteiam a identidade malaia e os desafios advindos das mais recentes migrações: os novos migrantes indianos ligados à indústrias e corporações e os estudantes chineses de vida transnacional.

Outra contribuição importante do livro para o estudo do multiculturalismo consiste no resgate desse modelo como discurso e prática, o que se realiza por meio de revisão bibliográfica e pela análise ampla tanto dos estereótipos e discursos da população singapurense quanto das políticas do Estado, ambos fundamentados em categorias racializadas de etnicidade e cultura. Assim, a relevante análise da construção discursiva e das políticas de formação dessas categorias, denominado como processo histórico de racialização, apresenta-se como essencial para a compreensão do processo de construção de uma identidade nacional afirmada multicultural/multirracial e dos consequentes processos de 
inclusão e exclusão derivados do quadrinômio simplificado e racializado: CMIO. Portanto, para melhor compreensão do leitor, o capítulo sexto, denominado The Politics of Racialization and Malay Identity, deveria preceder os capítulos que versam sobre as identidades excluídas dos Tamil Muslim e dos Ceylon-Tamils visto que estas exclusões também se fundamentam no processo de racialização, somente explicado posteriormente.

Por fim, é importante destacar que a ausência de uma conclusão capaz de associar as contribuições dos artigos reunidos, apesar de deixar livre essa tarefa ao leitor, prejudica a apreensão dos objetivos e resultados da obra. Ademais, mesmo que tenha construído uma expectativa inicial no que diz respeito a diferenciação dos multiculturalismos dos Estados liberais, como o Canadá, e dos comunitários, como o de Singapura, a tarefa de diferenciação do processo de formação da identidade multicultural não é retomada ao longo da obra.

Apesar disso, consegue-se depreenderque a formação histórica da identidade nacional singapurense baseia-se no discurso e nas políticas multiculturalistas pós-independências, mas que são configuradas como multirraciais devido ao processo de racialização anterior. Contudo, essa identidade multicultural não se mostra inclusiva, visto que se baseia em um quadrinômio simplificado que desvaloriza as diferenças existentes entre as etnias do quadrinômio, bem como as identidades excluídas desse. Assim, a obra contribui para os estudos do multiculturalismo por analisar os desafios e problemas na aplicação desse modelo por meio de análises históricas profundas e originais. 


\section{Referências:}

KYMLICA, W. Ciudadanía multicultural: Una teoría liberal de los derechos de las minorías. Barcelona: Editorial Paidós, 1996.

LIAN, K. F. Multiculturalism, Migration, and the Politics of Identity in Singapore. Brunei: Editora UBD, 2015.

OKIN, S. M. O multiculturalismo é ruim para as mulheres? Brasília: Revista Brasileira de Ciência Política, n.4, 2010.

SAID, E. W. Orientalismo: o oriente como invenção do ocidente. São Paulo: Companhia das Letras, 1996. 